\title{
00s' Animation Impact on Teenager Frustration Psychology
}

\author{
Jingqi Zhang, Rong Fan* \\ Shanghai University of Engineering Science, Shanghai, China
}

\begin{abstract}
How to cite this paper: Zhang, J. Q., \& Fan, R., (2017). 00s' Animation Impact on Teenager Frustration Psychology. The Educational Review, USA, 2(1), 155-161.

http://dx.doi.org/10.26855/er.2018.01.005
\end{abstract}

*Corresponding author: Rong Fan, Ph.D., Shanghai University of Engineering Science, Shanghai, China.

\begin{abstract}
At the beginning of new China, Chinese animation advocated a new style, and made great achievements in the world. After China's reform and opening up, Chinese animation has been impacted by foreign animation. The Chinese youth is mostly impacted by Japanese animation, which has brought positive influence on the youth in the early stage of Japanese economic development. However, since the Japanese economic bubble, some commercial animations have brought unhealthy content, which have a negative impact on young people. With the steady development of Chinese economy, Chinese animation is rising. However, due to the lack of core values, the value orientation of domestic animation is chaotic, which has a negative impact on the youth psychology. Therefore, it is imminent to actively respond to the socialist core values and explore the development of domestic virtuous animation.
\end{abstract}

\section{Keywords}

Teenager, Animation, Frustration Psychology

\section{Introduction}

As a form of artistic expression beloved by teenagers, animation has greatly influenced their psychology when teenagers are faced with frustration. Teenagers can think of how the so-and-so roles overcome difficulties in a difficult situation. And they can overcome difficulties like the main characters as well. However, in some animations, when main characters are faced with difficulties, they choose to escape and an unrealistic fantasy appears. Therefore, this paper discusses the influence of the 00s' animation on the psychology teenagers' frustration.

\section{Current Situation of 00s' Chinese Animation Development}

\subsection{The Impact of Japanese Animation}

After the Japanese economic bubble, Japanese animation begins to develop to the direction of "Abandoned lovely" culture and sustainable sequels. This is associated with the continued depression of Japanese economy. More animation producers would not like to take risks for innovation. More animations rely on "sexual connotation" to make sufficient attention, such as chest dodging bullets fragment (see Figure 1) inside High School Of The Dead. This has caused many works to lose their original meaning. In a work like Detective Conan, it has become an idol animation with Conan's various handsome behaviors by changing careful reasoning to the killer's face saying "I'm the killer". Although Japanese superb animations are a little less than before the new millennium, it still has a strong appeal to the offspring of China's 
middle class. Such teenager tend to be the "little prince" and "little princess" in the home. Fragile glass hearts make them to hide in the ivory tower created by Japanese animation to imagine something that would never happen around us.
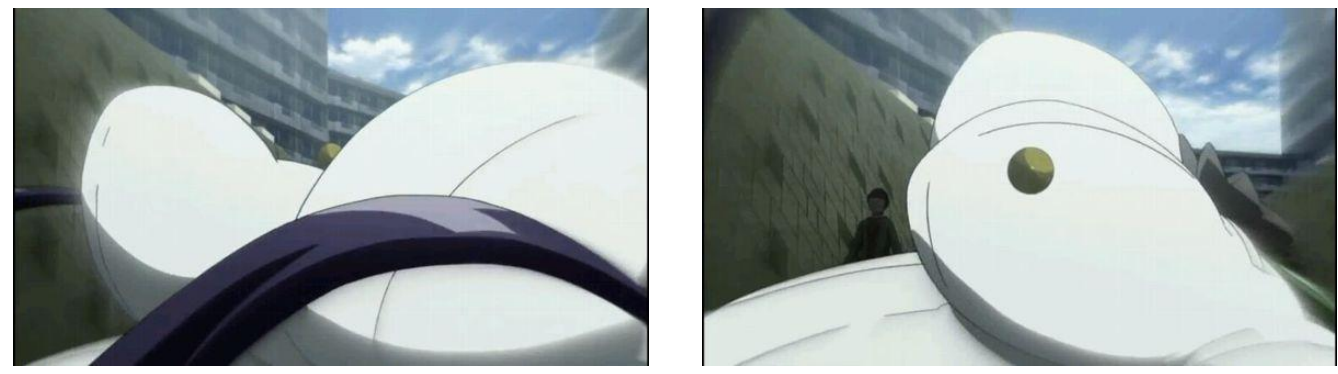

Figure 1. High school of the dead fragment.

\subsection{The Impact of American Animation}

American animations are mostly produced by Disney and DreamWorks. Compared with Japanese animation, American animation pays more attention to young and old. The first major advantage of American animation is that the amount of money invested is enormous, with Kung Fu Panda investing \$130 million, while the Chinese animated film the Lotus Lantern directed by Chang Guangxi is only invested 12 million yuan. Secondly, there are many production teams, which mainly ensure that American animation can produce two to three big-budget productions a year. Third, the production time is long. Disney's zootopia (see Figure 2) has been modified for five years over and over but never abandoned.

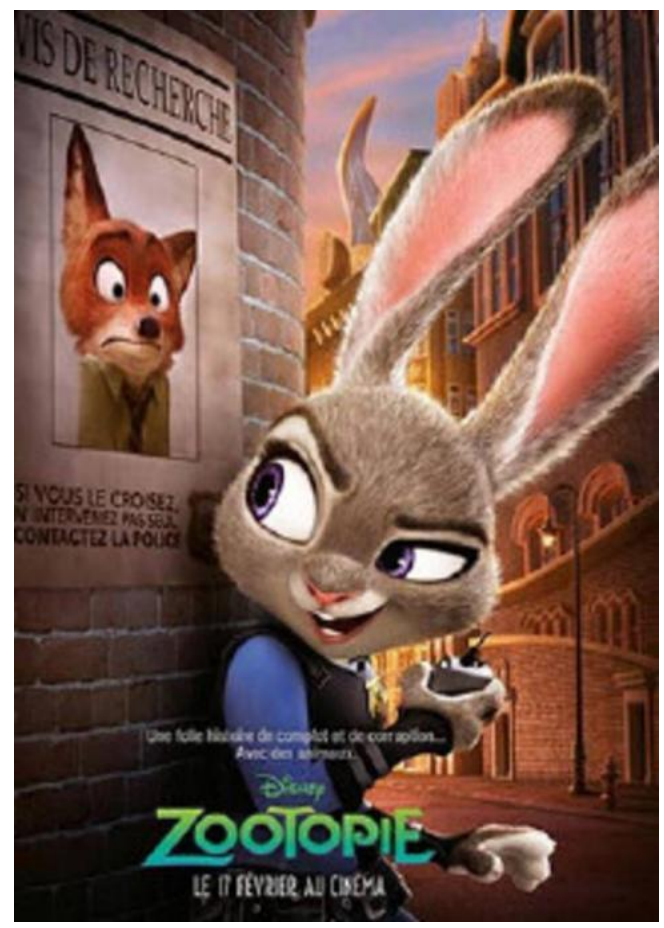

Figure 2. Zootopia.

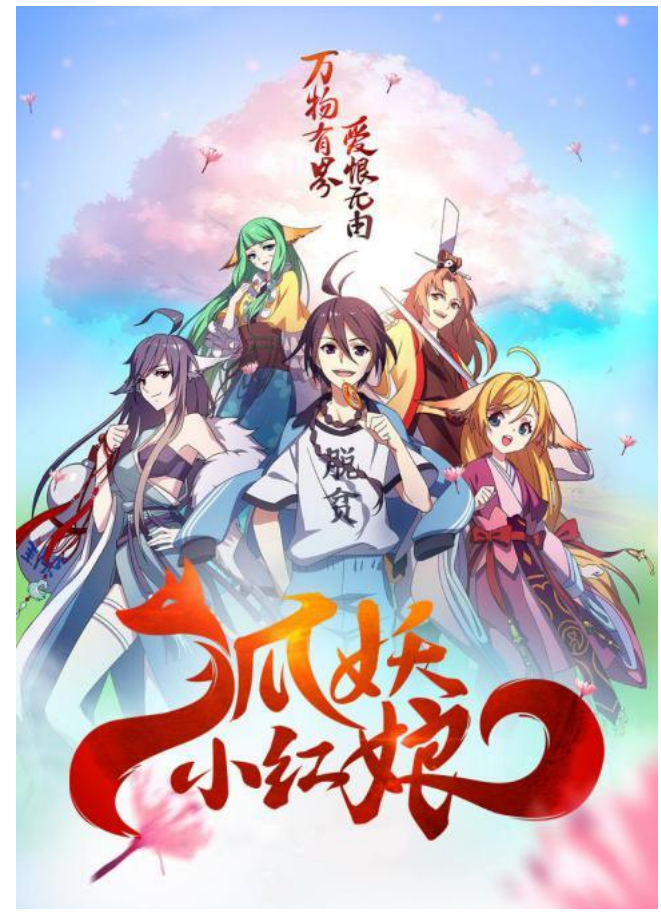

Figure 3. Little fox matchmaker. 


\subsection{The Difficult Development of Domestic Aanimation}

After the new millennium, with the Japanese economic bubble and the steady increase of China's overall strength, Chinese animation begins to rise. In the early stage, the animation rate of young children rise first, such as Three Thousand Questions of Blue Cat and Naughty, Blue Cat and Red Rabbit Descend from Tian Shan, Pleasant Goat and Big Big Wolf and so on. However, there are few animations for teenagers. Domestic youth animation such as Mad for music can't cope with excellent foreign animations such as One Piece, Naruto and Gintama. Today's Chinese animations such as Little Fox Matchmaker (see figure 3), Professional Master and so on, which are all about cooperating with Japan. So the image is very much like Japanese animation. In the face of squeeze of Japanese and American animation, it is difficult in taking a step for Chinese animation to walk out a new path.

\section{Influence of Teenager Psychological Analysis on Domestic Animation}

Adolescence period is the golden age of life, which is also a troubled times. In this period, various psychological contradictions and conflicts are intertwined, promoting the development of the mind and body of Teenagers. A variety of psychological problems can be expressed in this period. Various psychological problems may stem from this period. So the adolescence period is a critical period of life. Therefore, the mental health level of adolescence period affects his future growth and development and the personality traits formed during this period will determine the life course of his lifetime.

\subsection{The Influence of Psychological Analysis of Teenagers on Domestic Animation Style}

Many Teenagers want to be different from others in this time period. For the main characters in the animation, no matter how the modelling or the colors match is, the more outstanding, the better. They are not averse to the role of red hair, blue hair or purple hair. They don't wear the same clothes as others, because the more marked decoration is more representative of the concept of "self". This is especially prominent in Japanese animation, where "Straw Hat" can represent Monkey D Luffy in One Piece (see Figure 4) and "Rasengan" can represent Uzumaki Naruto in Naruto.

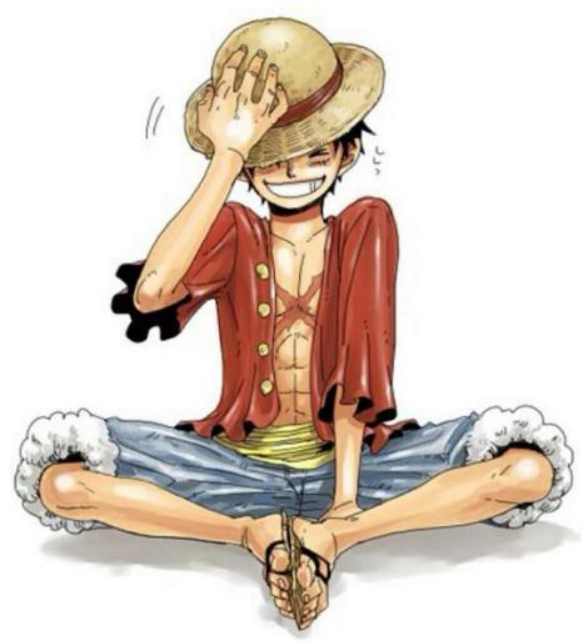

Figure 4. "Straw Hat" monkey D luffy. 


\subsection{The Influence of Psychological Analysis of Teenagers on Domestic Shooting Script}

Adolescence is a great time to fantasize about the opposite sex. They want to know about the opposite sex but they are afraid to let other know their secret. They want to be able to feel the sentimental love through the youth animation, and even some adults will come to see the youth animation in order to recall or make up for the lost feelings. Therefore, it is especially important to present the characters' emotions and feelings unspoken in the shooting script of animation.

Of course, because of mental incompleteness, the scene of bloody violence should be avoided. In order to show the plot of suicide of Nezha in the Prince Nezha's Triumph against Dragon King, the staff of Shanghai Animation Film Studio takes great pains to select the suicide scene of rotating Nezha at final to avoid splashes blood on the ground to scare the children.

\section{The Influence of 00s' Animation on the Frustration Psychology of Teenagers in 2004}

\subsection{Positive Influence}

\subsubsection{Relieve Psychological Pressure}

Teenagers want to separate themselves from their parents, but they can't get away from it. In the face of problems, they think they are adults and should be able to solve them. But usually they can't solve them. They have self-abasement or self-conceit. And the youth animation can alleviate the psychological pressure to a certain extent and the important friendship, family affection in life can be passed to the audience such as helping Nami to defeat the dragon pirates or saving her brother Ace in One Piece.

\subsubsection{Promotion of the Development of Teenager Thinking}

Teenagers are more likely to go to extremes without proper psychological guidance during this period. In the face of problems, developing thoughts and thinking calmly can figure out better solutions. In the case of the Penguins of Madagascar, there are different solutions to problems for the gang of four penguins. The animation also conveys the concept of solidarity and cooperation of a four-person team of American troops to the audience.

\subsection{Negative Influence}

\subsubsection{Knowledge Scraps}

The fragmented knowledge can't replace the systematic learning in school. Addicted to animation or the animation that is divorced from reality are not conducive to the development of teenagers. In Pleasant Goat and Big Big Wolf pleasant goat mostly won through "petty trick". And there are problems in the logic of the story. This will give viewers the illusion that "I can figure it out in due course".

\subsubsection{Guiding Chaos of Commercial Animation}

Commercial animation is more likely to attract others' attention, while the omission is the education of the teenager worldview. In Oreimo elder brother Kyousuke Kousaka has a love affair with his sister Kirino Kousaka. A lot of sister control appear. And even someone comments that "the country owes me a sister". For this incorrect orientation, on one

hand, it is the defiance of parents are disgusted with "puppy love". On the other hand, it is the longing for the opposite sex.

\section{Construction of a Cultural Situation of Teenager Psychological Education}

\subsection{Education Function Missing of Domestic Animation}




\subsubsection{Lack of Core Values}

In comparison to American animation pays attention to "family" and Japanese animation pays attention to "friendship", domestic animation has no particular focus. The Chinese traditional concepts of "Confucianism" and "Xia" are challenged by modern society. For the concept of "Xia", in the social development, the interests and morality produce great conflict, which becomes not easy to be clarified. "Xia" is the yearning for unfettered life, which represents the disconnection from modern society. In recent years "Confucianism" is beaten down in the Cultural Revolution. Then "stale and pedantic scholar" is also known as "keyboard man", who is hated by people on the Internet deeply. The so-called "experts" are described by the news media into a group of unreliable people. The most ambitious and most ideal "Confucianism" and "Xia" originally are in a slump in the modern society.

\subsubsection{Shortage of Innovative Talents}

It is called that "It is easy to get a thousand soldiers but hard to get a general". A large number of talents of domestic animation have flowed to Japan and the United States. The reason is the problem of economic development. As China's economy has grown steadily, more and more talents are pouring into the Chinese animation market. However, it is difficult to get started. And the Chinese people still have the voice that foreign animation is good. There is even denigration of domestic animation. In this case, the domestic animation still has made achievements. They even get some confidence. For example, when School Shock (see Fig.5) of "with sinister appearance" landed in Japan, nobody asked for it. The core problem is the shortage of talents. If there are no people who come out of domestic land, there won't be a touching story or a moving animation.

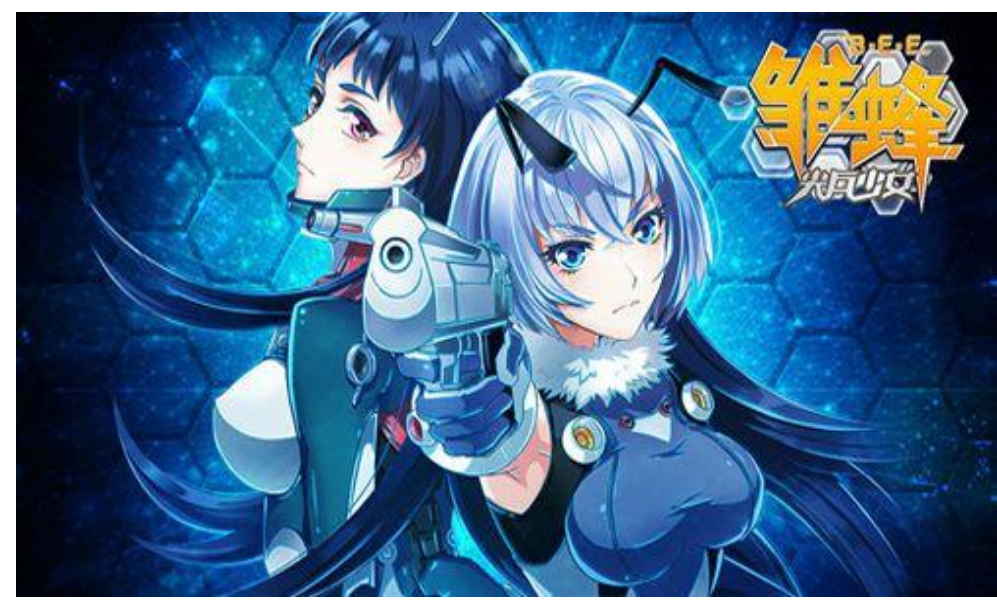

Figure 5. School shock.

\subsection{Measures of Construction of a Cultural Context of Teenager Psychological Education}

\subsubsection{Active Respond to the Core Socialist Values}

Socialist core values is the kernel of the system of socialist core values, which has reflected the fundamental nature and basic characteristics of the system, reflected the rich connotation and practical requirements of the system. And socialist core values are high concise and concentrated expression of the system of socialist core values. 
To realize the great Chinese dream, we must build core values that have strong cohesive force and inspirational force, which is related to social harmony and stability, related to national long-term stability. To achieve the objective of the struggle of "Two one hundred" and realize the Chinese dream of the great rejuvenation of the Chinese nation, we must rely on generations of teenagers and aspire to "read books for the rise of China". Therefore, we should actively respond to the core socialist values.

\subsubsection{Exploration of Benign Animation with Chinese Characteristics}

Since our country's first color animation Why the Crow is Black was mistaken for Soviet animation when it won a prize internationally, director of Shanghai Animation Film Studio Te Wei learns from the mistakes to determine to develop animation with Chinese characteristics. In the process, a series of potentially problematic animations have been "shot dead", such as the Black Cat Sheriff, Rubik's Cube Building, Shuke and Beta and so on. The author thinks that the benign animation with Chinese characteristics should have the following three characteristics.

First, it should stand for solidarity and cooperation. Xuncius argues that human being cannot run fast as a horse or swim well as a fish in this world, so that we should form a society to survive. Solidarity and cooperation has always been the key for Chinese nation to stand tall in the world. In China's famous paper-cut animation Calabash Brothers, each brother has their own unique ability. When they go to save grandpa one by one, the result can only be failure. And when they finally unite together, the snake essence and scorpions are beaten down. In the face of the disintegration by the enemy, teenagers should even more have a rational mind that only solidarity and cooperation can overcome the difficulties together when facing setbacks. In Calabash Brothers II snake essence's sister adopts the method of disintegration to cut down the rock mountain formed by calabash brothers into a piece by a piece and beats them respectively. Finally the hearts of seven calabash brothers are closely linked together into a white brother to overcome difficulties once again.

Second, it should advocate equality between men and women. Chinese women have always had great autonomy. Chairman Mao proposed that "Women hold up half the sky". In the construction of Chinese socialism, women can also contribute their own strength as men. Teenagers are full of curiosity about the opposite sex during the critical period of physical and mental development. When encountering setbacks on the interaction with opposite sex, it is unwise to treat men and women relation like "master and slave relationship" advocated by Japanese animation. In the animation Butterfly Dream: Liang Shanbo and Zhu Yingtai, their sad and beautiful love story aims to object to the arranged marriage in old society and advocate free love. As a teenager, it is also important to recognize that in terms of communication, not only the choice of men should be respected, but also the choice of women.

Third, it should have traditional Chinese elements. The reason why an animation is a Chinese one is because it has the uniqueness of China and this uniqueness comes from the traditional Chinese culture. Our ancestors have contributed a lot of fables and fairy tales for us, such as Joson butterfly dream, fish trapped in a dry rut, keep the glittering casket and give back the pearls to the seller, wait for windfalls and so on. The ancient wisdom is the source of our inspiration. When these Chinese elements collide with western culture, they will produce new animations such as Kung Fu Panda, Hua Mulan and so on.

\section{Conclusion}

After China's reform and opening up, Chinese animation is impacted by foreign animation. Chinese young generation is influenced mostly by Japanese animation. Since Japan's economic bubble, some Japanese commercial animations have brought unhealthy tendency, which has brought negative influence to teenagers. With the steady development of China's economy, Chinese animations begin to rise. In order to build a good youth psychology education environment, it is a 
positive development direction through actively responding to the core socialist values and exploring the benign animation with Chinese characteristics.

\section{References}

Chen, W., \& Ge, S. Y. (2016). Primary Investigation of Psychological Function of the Rhythm of Animated Films. Art Science and Technology, 08, 103-134.

Huang, X. Y. (2016). Color and Psychology - the Use of Color Language in the Pixar Animation Inside Out. Art and Literature for the Masses, (11):86.

Li, S. F. (2016). The Application of Audience Psychoanalysis in Short Animation Film Creation. Hunan Packaging, $03,32-34$.

Si, G. S. (2016). Humble Opinion of Motion Graphic Animation. Art Science and Technology, 07, 66.

Yan, M., \& Zheng, C. (2016). Regulation Function of "Healing Animation" to the Audience's Emotions. Journal of News Research, 08, 25-26.

Zhang, C. (2016). Trauma and Stereotypes-Psychology Interpretation of Zootopia. Oriental Art, S1, 104-105.

Zhao, Y. L. (2016). Chinese Animation Creation and Youth Psychology Research. Shenyang Normal University.

Zhou, C. Y. (2006). Brief Discussion on the Development and Application of MG Animation in the New Media Environment. Art Panorama, 10, 138-139. 